TITLE:

\title{
Age- and hypertension-dependent changes in retinal vessel diameter and wall thickness: an optical coherence tomography study.
}

\section{AUTHOR(S):}

Muraoka, Yuki; Tsujikawa, Akitaka; Kumagai, Kyoko; Akiba, Masahiro; Ogino, Ken; Murakami, Tomoaki; AkagiKurashige, Yumiko; Miyamoto, Kazuaki; Yoshimura, Nagahisa

\section{CITATION:}

Muraoka, Yuki ...[et al]. Age- and hypertension-dependent changes in retinal vessel diameter and wall thickness: an optical coherence tomography study.. American journal of ophthalmology 2013, 156(4): 706-714.e2

\section{ISSUE DATE:}

2013-10

\section{URL:}

http://hdl.handle.net/2433/179294

\section{RIGHT:}

(c) 2013 Elsevier Inc.; この論文は出版社版でありません。引用の際には 出版社版をご確認ご利用ください。; This is not the published version. Please cite only the published version. 


\section{Elsevier Editorial System(tm) for American Journal of Ophthalmology Manuscript Draft}

Manuscript Number: AJO-13-329

Title: Age and Hypertension-Dependent Changes in Retinal Vessel Diameter and Wall Thickness: An Optical Coherence Tomography Study

Article Type: Original Article

Keywords:

Corresponding Author: Dr. AKITAKA TSUJIKAWA, M.D.

Corresponding Author's Institution: Kyoto University Graduate School of Medicine

First Author: Yuki Muraoka

Order of Authors: Yuki Muraoka; Kyoko Kumagai; AKITAKA TSUJIKAWA, M.D.; Masahiro Akiba; Ken Ogino; Tomoaki Murakami; Yumiko Akagi-Kurashige; Kazuaki Miyamoto; Nagahisa Yoshimura 


\section{ABSTRACT}

PURPOSE: To evaluate the reliability and validity of retinal vessel diameter measurements by optical coherence tomography (OCT). The effect of age and hypertension on vessel diameter is also examined.

DESIGN: Prospective, cross-sectional study.

METHODS: Two hundred and thirty-eight eyes (238 subjects) with no ocular disease were included. One hundred and six subjects had hypertension and 132 subjects did not. Spectralis HRA+OCT was used to scan a circular region around the optic disc. The outer and inner diameters of the 4 largest retinal arteries and veins were measured using vascular wall reflections on OCT, by which, vessel wall thickness was calculated.

RESULTS: Mean arterial and venous outer diameters were $122.5 \pm 10.9 \mu \mathrm{m}$ and $141.0 \pm$ 13.1 $\mu \mathrm{m}$, respectively. Mean arterial and venous inner diameters were $87.8 \pm 9.4 \mu \mathrm{m}$ and $113.7 \pm 12.5 \mu \mathrm{m}$, respectively. Mean arterial and venous diameter OCT measurements were significantly correlated to mean arterial and venous fundus photography caliber measurements. Arterial and venous wall thicknesses were $17.4 \pm 2.4 \mu \mathrm{m}$ and $13.7 \pm 2.1$ $\mu \mathrm{m}$, respectively, both of which were highly correlated with subject age (arterial: $r=0.612$, $P<.001$, venous: $r=0.455, P<.001)$. In addition, both mean arterial and venous wall thicknesses were significantly greater in subjects with hypertension than in age-matched subjects without hypertension ( $P=.020$ and .015 , respectively).

CONCLUSIONS: Retinal vessel diameter measurements obtained with OCT were highly reproducible. In addition, vessel walls calculated from outer-and inner-diameters were significantly thickened by both aging and systemic hypertension. 


\title{
Age and Hypertension-Dependent Changes in Retinal Vessel Diameter and Wall Thickness: An Optical Coherence Tomography Study
}

\author{
YUKI MURAOKA, ${ }^{1,3}$ KYOKO KUMAGAI, ${ }^{1,3}$ AKITAKA TSUJIKAWA,${ }^{1}$ MASAHIRO AKIBA, ${ }^{2}$ \\ KEN OGINO, ${ }^{1}$ TOMOAKI MURAKAMI, ${ }^{1}$ YUMIKO AKAGI-KURASHIGE, ${ }^{1}$ KAZUAKI \\ MIYAMOTO, ${ }^{1}$ and NAGAHISA YOSHIMURA ${ }^{1}$ \\ ${ }^{1}$ Department of Ophthalmology and Visual Sciences, Kyoto University Graduate School \\ of Medicine, Kyoto, Japan. \\ ${ }^{2}$ Topcon Corporation, Tokyo, Japan. \\ ${ }^{3}$ These two authors equally contributed to this paper.
}

Financial Support: This study was supported, in part, by the Japan Society for the Promotion of Science (JSPS), Tokyo, Japan (Grant-in-Aid for Scientific Research, no. 21592256) and the Japan National Society for the Prevention of Blindness, Tokyo, Japan.

Conflicts of Interest: Dr. Akiba is an employee of the Topcon Corporation.

Short title: Changes in Retinal Vessels Caused by Age and Hypertension

\author{
*Correspondence/ Akitaka Tsujikawa, MD \\ Reprint Requests: Department of Ophthalmology and Visual Sciences, \\ Kyoto University Graduate School of Medicine, \\ Sakyo-ku, Kyoto 606-8507, Japan. \\ E-mail: tujikawa@kuhp.kyoto-u.ac.jp
}


The retinal vasculature can be directly and noninvasively visualized through the transparent ocular media. This facilitates assessment of retinal vascular changes resulting from systemic and/or metabolic diseases.$^{1-3}$ Classically, funduscopic findings in the retinal vasculature (i.e., arteriolar narrowing, caliber irregularity, light reflex alterations, vessel wall sheathing, arteriovenous crossing phenomena) ${ }^{4}$ are categorized according to the Keith-Wagener-Barker ${ }^{5}$ and/or the Scheie classification systems, ${ }^{6}$ and are used to diagnose systemic arteriosclerosis or hypertension. In addition, recent semi-automated measurement software programs allow precise retinal vessel caliber measurements to be obtained from digital fundus photographs. ${ }^{7-11}$ Using these measurements, population-based studies examined risk factors for various diseases and found that an increased retinal venous caliber is associated with stroke ${ }^{12,13}$ and ischemic heart disease. ${ }^{14,15}$

In the past decade, advances in optical coherence tomography (OCT) image resolution and acquisition speed have allowed more detailed observations of the retinal architecture, which has greatly enhanced our understanding of the pathomorphology of various macular diseases. ${ }^{16-18}$ Unfortunately, retinal vasculature features have not been well-studied with OCT and the literature is sparse. ${ }^{19}$ Recently, Muraoka and associates ${ }^{20}$ obtained sectional OCT images of physiologically normal retinal vessels. Vessel cross-sections were usually oval in shape and appeared as 4 distinct hyper-reflectivities in a linear configuration. It was concluded that the innermost and outermost hyper-reflectivities were derived from the vessel wall itself, and that the internal paired hyper-reflectivities came from flowing blood. Because OCT has a higher resolution in the direction of the light beam, we assume that OCT allows for precise vertical diameter measurement of these retinal vessels. 
In the current study, we used Spectralis HRA+OCT to measure retinal vessel diameter and wall thickness in the region surrounding the optic disc. The repeatability and validity of these measurements was also evaluated in subjects without ocular and systemic disease. The influence of age and hypertension on retinal vessels was also examined using measurements from subjects without systemic hypertension, and from age-matched subjects with or without systemic hypertension.

\section{METHODS}

The Institutional Review Board and Ethics Committee of Kyoto University approved this study, which was conducted in accordance with the tenets of the Declaration of Helsinki. Written informed consent was obtained from each subject before any study procedures or examinations were performed.

- PATIENTS: This prospective study consisted of 238 eyes of 238 subjects with no ocular disease. All subjects had no systemic diseases, except for 106 subjects who had hypertension. Retinal vessels were examined with the Spectralis HRA+OCT (Heidelberg Engineering, Heidelberg, Germany) at the Kyoto University Hospital Department of Ophthalmology between October 2011 and December 2012. Eyes that had any of the following were excluded from the study: keratoconus, high myopia (more severe than -6 diopters), high astigmatism (more severe than \pm 3 diopters), best-corrected visual acuity worse than 20/25, prior intraocular surgery, or any co-existing ocular disease (e.g., glaucoma, diabetic retinopathy, retinal vein occlusion, age-related macular degeneration, senile cataract that diminished image quality). Subjects with systemic disease (i.e., diabetes, dyslipidemia, stroke, ischemic heart disease, or collagen disease), except for 
hypertension were also excluded.

Presence of hypertension was determined based on antihypertensive agent use or by a physician's diagnosis. After a comprehensive medical interview, refractive error was measured, keratometry was performed, and, after pupil dilation, 45 digital fundus photographs were obtained (TRC-50LX; Topcon, Tokyo, Japan; 3,216 $\times 2,136$ pixels). Finally, OCT examination was performed with the Spectralis HRA+OCT. A circular scan, with a diameter of $3.46 \mathrm{~mm}$, centered around the optic disc center was obtained (Figure 1). Each OCT A-scan had a depth of $2 \mathrm{~mm}$ and was comprised of 512 pixels, which provided a depth $\times$ transverse digital sampling of $3.87 \times 7.50 \mu \mathrm{m}$ per pixel. An average of 100 scans obtained at the same location was used as the each section.

\section{- MEASUREMENT OF RETINAL VASCULAR CALIBER ON FUNDUS}

PHOTOGRAPHS: We used $45^{\circ}$ digital fundus photographs, centered $5^{\circ}$ nasal to the fovea, to measure the retinal vessel caliber, as described previously. ${ }^{21,22}$ Briefly, fundus photographs were imported into computer-imaging software (IVAN, University of Wisconsin, Madison, WI), and the caliber of each vessel located $0.5-1$ disc diameter from the optic disc margin (zone B) was measured in a semi-automated fashion.

\section{- MEASUREMENT OF RETINAL VESSEL OUTER AND INNER DIAMETER AND VESSEL WALL THICKNESS USING OPTICAL COHERENCE TOMOGRAPHY: A} Spectralis HRA+OCT circular scan, centered on the optic disc, provides cross-sectional images of all major retinal arteries and veins (Figure 1). Major retinal vessels in the peripapillary area radiate from the optic disc and run parallel to the retinal surface. This allows OCT light to be projected vertically to the vessel walls and lumen. We measured 
the vessel diameters of the 4 largest retinal arteries and veins. As reported previously, normal vessels had heterogeneous reflectivity, appeared oval in shape, and often had 4 distinct hyper-reflectivities in a linear configuration (Figure 1). ${ }^{20}$ When the image horizontal:vertical ratio was changed back to $1: 1$, the vessel cross-sections became round (Figure 1). While retinal vessels sometimes showed a circular vascular wall (Figure 1), most appeared only as reflections from the inner (towards the vitreous) and outer (towards the retinal pigment epithelium [RPE]) sides of the vessel wall. Additionally, all flowing blood appeared inside the vessel as a paired hyper-reflectivity, which was frequently hourglass-shaped (Figure 1).

Using our OCT measurements, vessel wall thickness was calculated according to the following formula: wall thickness $=($ outer vessel diameter - inner vessel diameter $) / 2$. Masked retinal specialists measured outer and inner vessel diameter of the 4 largest arteries and 4 largest veins on each OCT scan.

\section{- REPRODUCIBILITY OF OPTICAL COHERENCE TOMOGRAPHY VESSEL}

DIAMETER MEASUREMENTS: Intervisit reproducibility of vessel diameter OCT measurements was examined in 25 subjects who underwent 2 OCT examinations by the same examiner at 2 different visits. Evaluations were performed 2 weeks to 3 months apart. Interexaminer reproducibility was examined in 20 subjects who underwent 2 OCT scans on the same date, each by a different independent examiner. Repeatability of vessel diameter measurements was examined by having 2 retina specialists independently measure vessel diameters on the same OCT scan in 50 subjects. The intraclass correlation coefficient (ICC) was used to determine repeatability using 1 randomly selected artery and 1 randomly selected vein in each subject's OCT scan. 
Additionally, mean outer and inner vessel diameters were calculated by averaging OCT measurements from the 4 largest arteries and veins. These were compared with mean vessel caliber measured on digital color fundus photographs with the assistance of semi-automated computer software.

\section{- EFFECT OF BLOOD FLOW ON VERTICAL VESSEL DIAMETER MEASUREMENT:}

The potential effect of blood flow on the OCT representation of retinal vessels was examined in vitro. A fine glass tube with an inner diameter of $140 \mu \mathrm{m}$ (AS ONE, Osaka, Japan) was connected to a pump to circulate heparinized human blood collected from healthy volunteers. Blood flow rates were selected arbitrarily and the tube was scanned using the Spectralis HRA+OCT. A 25-diopter lens was attached to the OCT machine to focus on the blood flow within the glass tube. Each final OCT image was obtained by averaging 100 scans. Previous studies have shown that flow velocity in the major retinal vessels of healthy eyes is approximately $5-35 \mathrm{~mm} / \mathrm{s}^{23}$ To be within both physiologically normal and pathological flow velocity ranges, blood flow rate within the glass tube was varied between 0.0 and $10.0 \mathrm{ml} / \mathrm{h}(0.0-180.5 \mathrm{~mm} / \mathrm{s})$.

- STATISTICAL ANALYSES: Statistical analyses were performed using PASW Statistics (version 18.0, SPSS, Chicago, IL). Vessel diameter values are presented as mean \pm standard deviation and were calculated using the 4 selected arteries or 4 selected veins on fundus photographs or OCT sections. Student's t- tests were used to compare quantitative data with normal distributions and equal variance. Distributions were examined for statistical differences with chi-square tests and bivariate relationships were analyzed using Pearson's correlation coefficient. Statistical significance was defined as a 
$P$ value $<.05$

\section{RESULTS}

The current study examined 238 eyes from 238 subjects (133 male subjects, 105 female subjects), both with and without hypertension. Mean subject age was $62.1 \pm 15.6$ years and ranged between 21 and 92 years (Table 1).

Reproducibility and validity of OCT measurements were examined in the eyes of healthy volunteers with no systemic disease. Intervisit $(n=25)$, interexaminer $(n=20)$, and interevaluator $(n=50)$ ICCs of randomly selected vessel measurements were all greater than 0.90 (Table 2). Therefore, OCT measurements of vessel diameter in the circular region around the optic disc are highly reproducible.

Mean outer and inner artery and vein diameters were calculated from the 4 largest arteries and 4 largest veins identified. Mean arterial and venous outer diameter was $122.5 \pm 10.9 \mu \mathrm{m}$ (range: 93.3-172.6 $\mu \mathrm{m}$ ) and 141.0 $\pm 13.1 \mu \mathrm{m}$ (range: 110.3-183.5 $\mu \mathrm{m}$ ), respectively, and mean inner arterial and venous diameters were $87.8 \pm 9.4 \mu \mathrm{m}$ (range: 65.3-143.4 $\mu \mathrm{m}$ ) and 113.7 \pm 12.5 (range: 78.8-148.5 $\mu \mathrm{m}$ ), respectively. Mean vessel calibers of arteries and veins in zone B (0.5-1 disc diameter from the optic disc margin), as measured on fundus photographs, averaged $102.9 \pm 12.0 \mu \mathrm{m}$ (range: $76.2-158.9 \mu \mathrm{m}$ ) and $123.3 \pm 17.1 \mu \mathrm{m}$ (range: $59.2-169.7 \mu \mathrm{m}$ ), respectively. Table 3 shows the correlations between mean vessel diameter, as measured on OCT scans, and mean vessel caliber, as measured on fundus photographs. Images from 50 randomly selected healthy subjects were used. Optical coherence tomography measurements of vessel diameter are done in the plane vertical to the retinal surface, but fundus photograph measurements are done in the coronal plane. Although these disparate methods 
measured vessel diameter in different planes, OCT and fundus photograph measurements were correlated for both arterial and venous diameter/caliber measurements.

As previously mentioned, vessel wall thickness was calculated from outer and inner vessel diameter measurements. Mean wall thickness was $17.4 \pm 2.4 \mu \mathrm{m}$ (range: 10.3-23.0 $\mu \mathrm{m}$ ) in arteries and $13.7 \pm 2.1 \mu \mathrm{m}$ (range: $10.1-21.8 \mu \mathrm{m}$ ) in veins. Additionally, arterial walls generally had a higher reflectivity than venous walls, and arterial walls were significantly thicker than venous walls $(P<.001)$.

Using measurements from healthy eyes in subjects with no systemic disease, age-dependent changes in vessels were evaluated (Table 4, Figure 2). Although mean venous outer and inner diameter was not affected by subject age, mean wall thickness significantly increased with age $(r=0.455, P<.001)$. Mean arterial inner diameter was also not significantly affected by subject age, but mean outer diameter $(r=0.384, P$ $<.001)$ and vessel thickness $(r=0.612, P<.001)$ progressively increased with age. Subjects were then divided into older ( $\geq 50$ years) and younger ( $<50$ years) groups (Table 5). Arterial outer diameter, arterial wall thickness, and venous wall thickness were significantly greater in older subjects than in younger subjects (Figure 3). Vessel walls were $17 \%$ and $22 \%$ thicker in veins and arteries, respectively, in older subjects compared to younger subjects.

The effects of hypertension on the retinal vasculature were also examined in older ( $\geq 50$ years) subjects. Table 6 shows OCT vessel measurements in eyes of subjects with hypertension and those of age-matched subjects without hypertension. There were no significant differences between the 2 groups in mean outer or inner diameter in either arteries or veins. However, both mean arterial and mean venous wall thicknesses were 
significantly greater in subjects with hypertension than in those without $(P=.020$ and .015 , respectively). Figure 4 shows the scatter plot of mean arterial and mean venous wall thickness and age. When eyes were divided into hypertension-positive and hypertension-negative groups, arterial and venous wall thicknesses in both groups were positively correlated with age.

We mimicked blood flow within the major retinal vessels using fine glass tubes, through which blood samples were pumped at different flow velocities and scanned with Spectralis HRA+OCT. These in vitro data were used to confirm that OCT measurements of retinal vessels were not heavily influenced by blood flow speed. Supplementary Figure 1 shows cross-sections of a glass capillary filled with human blood, as represented on OCT. Blood in the glass tube without flow $(0 \mathrm{~mm} / \mathrm{sec})$ showed no paired hyper-reflectivity, but increasing blood flow velocity resulted in the development of a heterogeneous, hourglass-shaped hyper-reflectivity within the glass tube. However, blood flow changes had no effect on the measurement of the glass capillary vertical diameters.

\section{DISCUSSION}

Recently, Muraoka and associates ${ }^{20}$ reported that on OCT, physiologically normal retinal vessels are represented as oval-shaped configurations with 4 distinct hyper-reflectivities. In that report they concluded that, intermediate paired hyper-reflectivities, which are frequently hourglass-shaped and occasionally double "c" patterned, resulted from blood flow within retinal vessels. Cimalla and associates ${ }^{24}$ reported similar findings in both experimental animals and in glass tubes with flowing blood. The authors speculated that the unique paired hyper-reflectivities arose from a combination of shear-induced red blood cell alignment in vessels and vessel geometry. ${ }^{24}$ 
In the current study, we obtained retinal sections from a circular scan surrounding the optic disc. Because all major retinal vessels radiate from the optic disc, running parallel to the retinal surface, and the OCT beam is projected perpendicular to the retinal surface, vertical sections of all major retinal vessels were reliably obtained with a single scan. As shown in Figure 1, vascular walls sometimes appeared circular in our OCT sections, but most OCT sections showed only hyper-reflectivities from the outer and inner sides of vessel walls, where projected OCT light was perpendicular to the vessel wall. We used these reflections to measure the outer and inner vessel diameters in the vertical direction only. It was sometimes difficult to precisely determine vessel borders in the transverse direction on the OCT scan because of the lower reflectivity from the vessel walls. Furthermore, vessel diameters in the transverse direction could not be measured correctly when they were obliquely sectioned. In the present study, all intervisit, interexaminer, and interevaluator ICCs for OCT vessel diameter measurement were greater than 0.90, and thus, highly reproducible.

As shown in Table 3, the mean vessel diameters, as measured with OCT, were significantly correlated with mean vessel calibers, as measured on fundus photographs. Still, it should be noted that the Spectralis HRA+OCT circular scan (centered on the optic disc) had a radius of $1.73 \mathrm{~mm}$, slightly outside fundus photograph zone B (0.5-1 disc diameter from the optic disc margin), where vessel caliber measurements were measured with the assistance of IVAN. Additionally, vessel diameters were measured in different directions by fundus photograph.

We also used OCT measurements to calculate the thickness of retinal vessel walls. Arterial and venous wall thicknesses averaged $17.4 \pm 2.4 \mu \mathrm{m}$ (range: 10.3-23.0 $\mu \mathrm{m})$ and $13.7 \pm 2.1 \mu \mathrm{m}$ (range: $10.1-21.8 \mu \mathrm{m}$ ), respectively. This is in agreement with Hogan, ${ }^{25}$ 
who reported that the retinal arterial wall had 5-7 layers of smooth muscle cells and a thickness of approximately $18 \mu \mathrm{m}$ near the optic disc. Our results also agree with those reported by Raff and associates ${ }^{26}$ and Lehmann and Schmieder ${ }^{27}$ who studied the retinal arteriolar wall thickness using scanning laser Doppler flowmetry. Retinal arteriole wall thickness was $13.0 \pm 2.5 \mu \mathrm{m}$ at a location $2-3 \mathrm{~mm}$ superotemporal to the optic disc. ${ }^{26}$ Although only limited information is available on retinal vessel wall thickness, our OCT measurements are thought to be quite close to previous estimates obtained through histological measurements, as well as by other modalities.

Previous fundus photography studies, which included a large number of eyes, have reported an age-dependent reduction in major retinal artery and vein caliber., $28-30$ We also examined age-dependent changes in the retinal vasculature using OCT in subjects without hypertension (Table 4, Figure 2). Mean inner diameter did not change with subject age, and we speculate that this was due, at least in part, to our small sample size. However, retinal vessel wall thickness, particularly arterial wall thickness, significantly increased with subject age, despite our small sample size. Additionally, in older subjects ( $\geqq 50$ years old), mean venous and arterial wall thickness was $17 \%$ and $22 \%$ greater than those in younger subjects.

The effects of systemic hypertension on retinal vascular caliber were studied using thousands of fundus photographs in various population-based studies. The Atherosclerosis Risk In Communities ${ }^{31}$ and the Beaver Dam Eye Study ${ }^{32}$ reported negative correlations between blood pressure and retinal arteriolar diameter. The Blue Mountains Eye Study ${ }^{30}$ showed an increase in retinal venular caliber that was associated with hypertension. However, in the current study, we did not find any significant effects of systemic hypertension on either retinal arterial or retinal venous vessel diameter. We 
believe this result differed from previous larger studies because of our relatively small sample size. Interestingly, our OCT examinations did show a significant increase in retinal arterial and venous wall thickness in subjects with systemic hypertension, in comparison with the corresponding values in subjects who did not. Retinal vessel wall thickness may be more sensitive than vessel diameter to systemic hypertension. Because our data were not adjusted for factors such as diabetes, dyslipidemia, or smoking, we cannot say how other systemic factors contribute to retinal vessel wall changes.

Arteriosclerosis in large elastic arteries is characterized by patchy, nodular, and fatty infiltrations in the intima, and by fibrosis, ${ }^{33}$ which often predisposes patients to stroke and ischemic heart disease. In cardiology and neurology, increased arterial wall thickness and lumen narrowing are considered important factors in arteriosclerosis assessments. ${ }^{34-37}$ Intima-media thickness can be precisely measured in the coronary arteries with intravascular OCT, but this procedure is highly invasive. ${ }^{35,37-41}$ In a previous histological study, it was reported that arteriosclerotic changes in retinal arteries were somewhat different from those seen in large elastic arteries, ${ }^{33}$ but that retinal arteries always accompanied the wall thickening as a result of intimal hyalinization, endothelial hyperplasia, and medial hypertrophy. ${ }^{42}$ However, to date, there is no established method to evaluate arteriosclerotic changes in the human retina.

Some investigators believe that vertical elongation of retinal vessels occurs in OCT sections. In the present study, vessel diameters were measured on OCT images shown at a vertical/horizontal scale ratio of $2: 1$, in which retinal vessels were seen to have an oval configuration. However, when the scale ratio was changed to $1: 1$, vessel sections appeared round. Additionally, we examined the effect of blood flow on retinal 
vessel representation on OCT using in vitro measurements. Blood samples were pumped through glass tubes at different flow velocities and scanned with the Spectralis HRA+OCT. As shown in Supplementary Figure 1, the measured vertical diameter of the glass capillary tube was not dependent on blood flow velocity. Additionally, the external limiting membrane-line, the photoreceptor inner-outer segment junctions, and the RPE lines showed no faulting beneath major retinal vessels on OCT images. This suggests that the refractive index difference between retinal parenchyma and retinal vessels (red blood cells) was too small to cause image distortion.

- STUDY LIMITATIONS: The major limitations of our study are its small sample size, which resulted in a reduced statistical power. In addition, retinal vessel diameters were measured manually on OCT sections and automated software is needed to further standardize measurement methods. Moreover, as noted earlier, systemic conditions such as diabetes, dyslipidemia, and smoking history were not examined in our study. However, despite these shortcomings, we have demonstrated that measurement of retinal vessel diameter with OCT is highly reproducible, and that results are correlated with fundus photograph measurements. In addition, we were able to demonstrate that increased vessel wall thickness in both arteries and veins is strongly correlated with aging. Furthermore, vessel wall thickness is modified by systemic hypertension. Due to its noninvasive nature, OCT measurement of retinal vessel diameters and wall thickness has considerable potential for evaluating retinal arteriosclerotic changes, along with systemic disease associations. 


\section{ACKNOWLEDGMENTS}

A. Funding/Support: This study was supported, in part, by the Japan Society for the Promotion of Science (JSPS), Tokyo, Japan (Grant-in-Aid for Scientific Research, no. 21592256) and the Japan National Society for the Prevention of Blindness, Tokyo, Japan.

B. Financial Disclosure: M. Akiba, Topcon Corporation (Employment), N. Yoshimura, Topcon Corporation (Financial Support), Nidek (Financial Support, Consultant), Canon (Financial Support).

C. Contributions of Authors: Conception and design of the study (YM, KK, AT); analysis and interpretation (YM, KK, AT, KO, TM, YA-K, KM, NY); writing of the article (YM, KK, AT); critical revision of the article (KO, TM, YA-K, KM, NY); final approval of the article (YM,KK, AT, KO, TM, YA-K, KM, NY); data collection (YM, KK, AT, KO, TM, YA-K, KM). D. Ethics Committee Approval: The Institutional Review Board and Ethics Committee of Kyoto University approved this prospective study, which adhered to the tenets of the Declaration of Helsinki. Written informed consent for research participation was obtained from each subject before examination.

E. Other Acknowledgments: We are grateful to Prof. Nicola Ferrier, Department of Ophthalmology and Visual Sciences, University of Wisconsin-Madison, for the gift of IVAN, the computer-based program. 


\section{REFERENCES}

1. Wong TY, Mitchell P. Hypertensive retinopathy. N Engl J Med 2004;351(22):2310-2317.

2. Antonetti DA, Klein R, Gardner TW. Diabetic retinopathy. N Engl J Med 2012;366(13):1227-1239.

3. Schmieder RE. Hypertensive retinopathy: a window to vascular remodeling in arterial hypertension. Hypertension 2008;51(1):43-44.

4. Gunn M. On ophthalmoscopic evidence of general arterial disease. Trans Ophthalmol Soc UK 1898;18:356-381

5. Keith NM, Wagener HP, Barker NW. Some different types of essential hypertension: their course and prognosis. Am J Med Sci 1939;268:336-345.

6. Scheie HG. Evaluation of ophthalmoscopic changes of hypertension and arteriolar sclerosis. Arch Ophthalmol 1953;49:117-138.

7. Klein R, Klein BE, Moss SE, Wang Q. Hypertension and retinopathy, arteriolar narrowing, and arteriovenous nicking in a population. Arch Ophthalmol 1994;112(1):92-98.

8. Klein R, Klein BE, Moss SE, Wong TY, Sharrett AR. Retinal vascular caliber in persons with type 2 diabetes: the Wisconsin Epidemiological Study of Diabetic Retinopathy: XX. Ophthalmology 2006;113(9):1488-1498.

9. Alibrahim E, Donaghue KC, Rogers S, et al. Retinal vascular caliber and risk of retinopathy in young patients with type 1 diabetes. Ophthalmology 2006;113(9):1499-1503.

10. Nguyen TT, Wang JJ, Wong TY. Retinal vascular changes in pre-diabetes and prehypertension: new findings and their research and clinical implications. 
Diabetes Care 2007;30(10):2708-2715.

11. Roy MS, Klein R, Janal MN. Retinal venular diameter as an early indicator of progression to proliferative diabetic retinopathy with and without high-risk characteristics in African Americans with type 1 diabetes mellitus. Arch Ophthalmol 2011;129(1):8-15.

12. Ikram MK, de Jong FJ, Bos MJ, et al. Retinal vessel diameters and risk of stroke: the Rotterdam Study. Neurology 2006;66(9):1339-1343.

13. Nguyen TT, Islam FM, Farouque HM, et al. Retinal vascular caliber and brachial flow-mediated dilation: the Multi-Ethnic Study of Atherosclerosis. Stroke 2010;41(7):1343-1348.

14. Wong TY, Kamineni A, Klein R, et al. Quantitative retinal venular caliber and risk of cardiovascular disease in older persons: the cardiovascular health study. Arch Intern Med 2006;166(21):2388-2394.

15. Wang JJ, Liew G, Wong TY, et al. Retinal vascular calibre and the risk of coronary heart disease-related death. Heart 2006;92(11):1583-1587.

16. Ota M, Tsujikawa A, Murakami T, et al. Foveal photoreceptor layer in eyes with persistent cystoid macular edema associated with branch retinal vein occlusion. Am J Ophthalmol 2008;145(2):273-280.

17. Tsujikawa A, Sakamoto A, Ota M, et al. Serous retinal detachment associated with retinal vein occlusion. Am J Ophthalmol 2010;149(2):291-301 e295.

18. Horii T, Murakami T, Nishijima K, et al. Relationship between Fluorescein Pooling and Optical Coherence Tomographic Reflectivity of Cystoid Spaces in Diabetic Macular Edema. Ophthalmology 2012;119(5):1047-1055.

19. Goldenberg D, Soiberman U, Loewenstein A, Goldstein M. Heidelberg 
spectral-domain optical coherence tomographic findings in retinal artery macroaneurysm. Retina 2012;32(5):990-995.

20. Muraoka Y, Tsujikawa A, Murakami T, et al. Morphologic and functional changes in retinal vessels associated with branch retinal vein occlusion. Ophthalmology 2013;120(1):91-99.

21. Hubbard LD, Brothers RJ, King WN, et al. Methods for evaluation of retinal microvascular abnormalities associated with hypertension/sclerosis in the Atherosclerosis Risk in Communities Study. Ophthalmology 1999;106(12):2269-2280.

22. Mosher A, Klein BE, Klein R, Knudtson MD, Ferrier NJ. Comparison of retinal vessel measurements in digital vs film images. Am J Ophthalmol $2006 ; 142(5): 875-878$.

23. Riva CE, Grunwald JE, Sinclair SH, Petrig BL. Blood velocity and volumetric flow rate in human retinal vessels. Invest Ophthalmol Vis Sci 1985;26(8):1124-1132.

24. Cimalla P, Walther J, Mittasch M, Koch E. Shear flow-induced optical inhomogeneity of blood assessed in vivo and in vitro by spectral domain optical coherence tomography in the 1.3 mum wavelength range. J Biomed Opt $2011 ; 16(11): 116020$.

25. Hogan MJ, Alvarado JA, Weddell JE. Histology of the Human Eye: An Atlas and Textbook. Philadelphia, PA:WB Saunders Co.;1971:393-522.

26. Raff U, Harazny JM, Titze SI, Schmidt BM, Michelson G, Schmieder RE. Salt intake determines retinal arteriolar structure in treatment resistant hypertension independent of blood pressure. Atherosclerosis 2012;222(1):235-240.

27. Lehmann MV, Schmieder RE. Remodeling of retinal small arteries in 
hypertension. Am J Hypertens 2011;24(12):1267-1273.

28. Kawasaki R, Wang JJ, Rochtchina E, et al. Cardiovascular risk factors and retinal microvascular signs in an adult Japanese population: the Funagata Study. Ophthalmology 2006;113(8):1378-1384.

29. Klein R, Klein BE, Moss SE, et al. Retinal vascular abnormalities in persons with type 1 diabetes: the Wisconsin Epidemiologic Study of Diabetic Retinopathy: XVIII. Ophthalmology 2003;110(11):2118-2125.

30. Leung H, Wang JJ, Rochtchina E, et al. Relationships between age, blood pressure, and retinal vessel diameters in an older population. Invest Ophthalmol Vis Sci 2003;44(7):2900-2904.

31. Sharrett AR, Hubbard LD, Cooper LS, et al. Retinal arteriolar diameters and elevated blood pressure: the Atherosclerosis Risk in Communities Study. Am J Epidemiol 1999;150(3):263-270.

32. Wong TY, Klein R, Klein BE, Meuer SM, Hubbard LD. Retinal vessel diameters and their associations with age and blood pressure. Invest Ophthalmol Vis Sci 2003;44(11):4644-4650.

33. Kimura T, Mizota A, Fujimoto N, Tsuyama Y. Light and electron microscopic studies on human retinal blood vessels of patients with sclerosis and hypertension. Int Ophthalmol 2005;26(4-5):151-158.

34. Degnan AJ, Young VE, Gillard JH. Advances in noninvasive imaging for evaluating clinical risk and guiding therapy in carotid atherosclerosis. Expert Rev Cardiovasc Ther 2012;10(1):37-53.

35. Yabushita H, Bouma BE, Houser SL, et al. Characterization of human atherosclerosis by optical coherence tomography. Circulation 
2002;106(13):1640-1645.

36. Clevert DA, Sommer WH, Helck A, Saam T, Reiser M. Improved carotid atherosclerotic plaques imaging with contrast-enhanced ultrasound (CEUS). Clin Hemorheol Microcirc 2011;48(1):141-148.

37. Kume T, Akasaka T, Kawamoto T, et al. Assessment of coronary intima--media thickness by optical coherence tomography: comparison with intravascular ultrasound. Circ J 2005;69(8):903-907.

38. Tearney GJ, Regar E, Akasaka T, et al. Consensus standards for acquisition, measurement, and reporting of intravascular optical coherence tomography studies: a report from the International Working Group for Intravascular Optical Coherence Tomography Standardization and Validation. J Am Coll Cardiol 2012;59(12):1058-1072.

39. Brezinski ME, Tearney GJ, Bouma BE, et al. Optical coherence tomography for optical biopsy. Properties and demonstration of vascular pathology. Circulation 1996;93(6):1206-1213.

40. Bezerra HG, Costa MA, Guagliumi G, Rollins AM, Simon DI. Intracoronary optical coherence tomography: a comprehensive review clinical and research applications. JACC Cardiovasc Interv 2009;2(11):1035-1046.

41. Lowe HC, Narula J, Fujimoto JG, Jang IK. Intracoronary optical diagnostics current status, limitations, and potential. JACC Cardiovasc Interv $2011 ; 4(12): 1257-1270$.

42. Green WR. Retina. In: Spencer WH, ed. Ophthalmic Pathology: An Atlas and Textbook. Vol 2. 4th ed. Philadelphia, PA: Saunders; 1996:1108-24. 


\section{FIGURE CAPTIONS}

FIGURE 1. Retinal vessel optical coherence tomography (OCT) cross-sections from circular scans surrounding the optic disc. (Top left) Infrared image. A circular OCT scan was performed along the green arrow. (Top right) Corresponding sectional OCT image. All major retinal vessels are represented as a group of heterogeneous reflectivities in an oval-shaped configuration (vertical:horizontal ratio $=2: 1$ ). (Bottom left) Magnified OCT image (white square in panel top row-right). The innermost and outermost hyper-reflectivities are the top and bottom of the vessel walls. (Bottom middle) An OCT image with a corrected vertical:horizontal ratio (from 2:1 to 1:1, same area as panel Bottom left). Retinal vessel sections now appear round. (Bottom right) Magnified OCT image of a retinal artery. A circular vascular wall can be seen.

FIGURE 2. Effects of age on mean arterial outer diameter (Top left, $r=0.384, P<.001$ ), mean arterial inner diameter (Top middle), mean arterial wall thickness (Top right, $r=$ $0.612, P<.001$ ), mean venous outer diameter (Bottom left), mean venous inner diameter (Bottom middle), and mean venous wall thickness (Bottom right, $r=0.455, P<.001$ ) in subjects without systemic or ocular disease.

FIGURE 3. Increased thicknesses of arterial and venous walls in an older subject. (Top left) Fundus photograph from a 32-year-old man with no ocular disease. (Top middle) Corresponding infrared image. Optical coherence tomography (OCT) cross-section obtained along the green circular arrow. Red arrows indicate retinal arteries, and blue arrows indicate retinal veins. (Top right) Retinal vessels, as represented on OCT images. (Bottom left) Fundus photograph from a 70-year-old man with no ocular or systemic 
disease. (Bottom middle) Corresponding infrared image. The OCT cross-section obtained along the green circular arrow. Red arrows indicate retinal arteries, blue arrows indicate retinal veins. (Bottom right) Retinal vessels, as represented on OCT images. Note the thicker venous and arterial walls and the stronger vessel wall reflectivity in the older subject.

FIGURE 4. Scatter plot of mean arterial and venous wall thickness vs. age. When eyes were divided into hypertension-positive and hypertension-negative groups, both arterial (Left) and venous (Right) wall thicknesses were positively correlated with age in both groups. In the hypertension-positive group, arterial and venous wall thicknesses were greater than those in the hypertension-negative group.

Supplementary FIGURE 1. Cross-sectional optical coherence tomography images (Spectralis HRA+OCT) of a blood-filled fine glass tube at different blood flow velocities. Note the homogeneous reflectivity with no blood flow (flow rate $=0 \mathrm{~mm} / \mathrm{sec}$ ). When blood flow velocity was increased, the single internal reflectivity became multiple heterogeneous, hourglass-shaped hyper-reflectivities. Glass tube vertical diameter measurements were not affected by changes in blood flow velocity. 
TABLE 1. Subject Characteristics

\begin{tabular}{cc}
\hline Age (years, range) & $62.1 \pm 15.6(21-92)$ \\
$20-39$ years $(\mathrm{n})$ & 51 \\
$40-59$ years $(\mathrm{n})$ & 142 \\
$60-79$ years $(\mathrm{n})$ & 17 \\
$80+\quad$ years $(\mathrm{n})$ & $133 / 105$ \\
Gender (male/female) & $106 / 132$ \\
Hypertension (+/-) & $-0.27 \pm 1.94$ \\
Refractive error (diopters) & $7.65 \pm 0.30$ \\
Keratometer reading (mm) & \\
\hline
\end{tabular}


TABLE 2. Intraclass Correlation Coefficient for Measuring Retinal Vessel Diameters by Optical Coherence Tomography

\begin{tabular}{lccc}
\hline & \multicolumn{3}{c}{ Intraclass Correlation Coefficient } \\
\cline { 2 - 4 } & Intervisit & Interexaminer & Interevaluator \\
& $(\mathrm{n}=25)$ & $(\mathrm{n}=20)$ & $(\mathrm{n}=50)$ \\
\hline Arterial outer diameter & 0.964 & 0.944 & 0.959 \\
Arterial inner diameter & 0.969 & 0.948 & 0.972 \\
Venous outer diameter & 0.977 & 0.958 & 0.980 \\
Venous inner diameter & 0.982 & 0.961 & 0.978 \\
\hline
\end{tabular}


TABLE 3. Correlations between Mean Retinal Vessel Diameter, as Measured on Optical Coherence Tomography Images and Fundus Photographs ( $n=50$ eyes)

\begin{tabular}{lcc}
\hline & $r$ & $P$ value \\
\hline Mean arterial outer diameter & 0.286 & .044 \\
Mean arterial inner diameter & 0.395 & .005 \\
Mean venous outer diameter & 0.450 & .001 \\
Mean venous inner diameter & 0.455 & .001 \\
\hline
\end{tabular}

Mean outer and inner vessel diameters were obtained by averaging values of the four largest vessels. Bivariate relationships were analyzed using Pearson's correlation coefficient. 
TABLE 4. Effect of Age on Retinal Vessel Measurements by Optical Coherence Tomography

$$
(n=133 \text { eyes })
$$

\begin{tabular}{lccc}
\hline & Mean \pm SD & $r$ & $P$ value \\
\hline Vessel measurements $(\mu \mathrm{m})$ & & & \\
Mean arterial outer diameter & $120.6 \pm 10.3$ & 0.384 & $<.001$ \\
Mean arterial inner diameter & $87.3 \pm 8.3$ & 0.098 & .262 \\
Mean arterial wall thickness & $16.6 \pm 2.6$ & 0.612 & $<.001$ \\
Mean venous outer diameter & $140.6 \pm 12.5$ & 0.146 & .094 \\
Mean venous inner diameter & $114.2 \pm 12.1$ & -0.004 & .964 \\
Mean venous wall thickness & $13.2 \pm 2.1$ & 0.455 & $<.001$ \\
\hline Means obtained by averaging values of the 4 largest retinal vessels. Subjects with hypertension \\
were excluded from this analysis.
\end{tabular}


TABLE 5. Retinal Vessel Optical Coherence Tomography Measurements in Younger and Older Subjects Without Systemic Hypertension

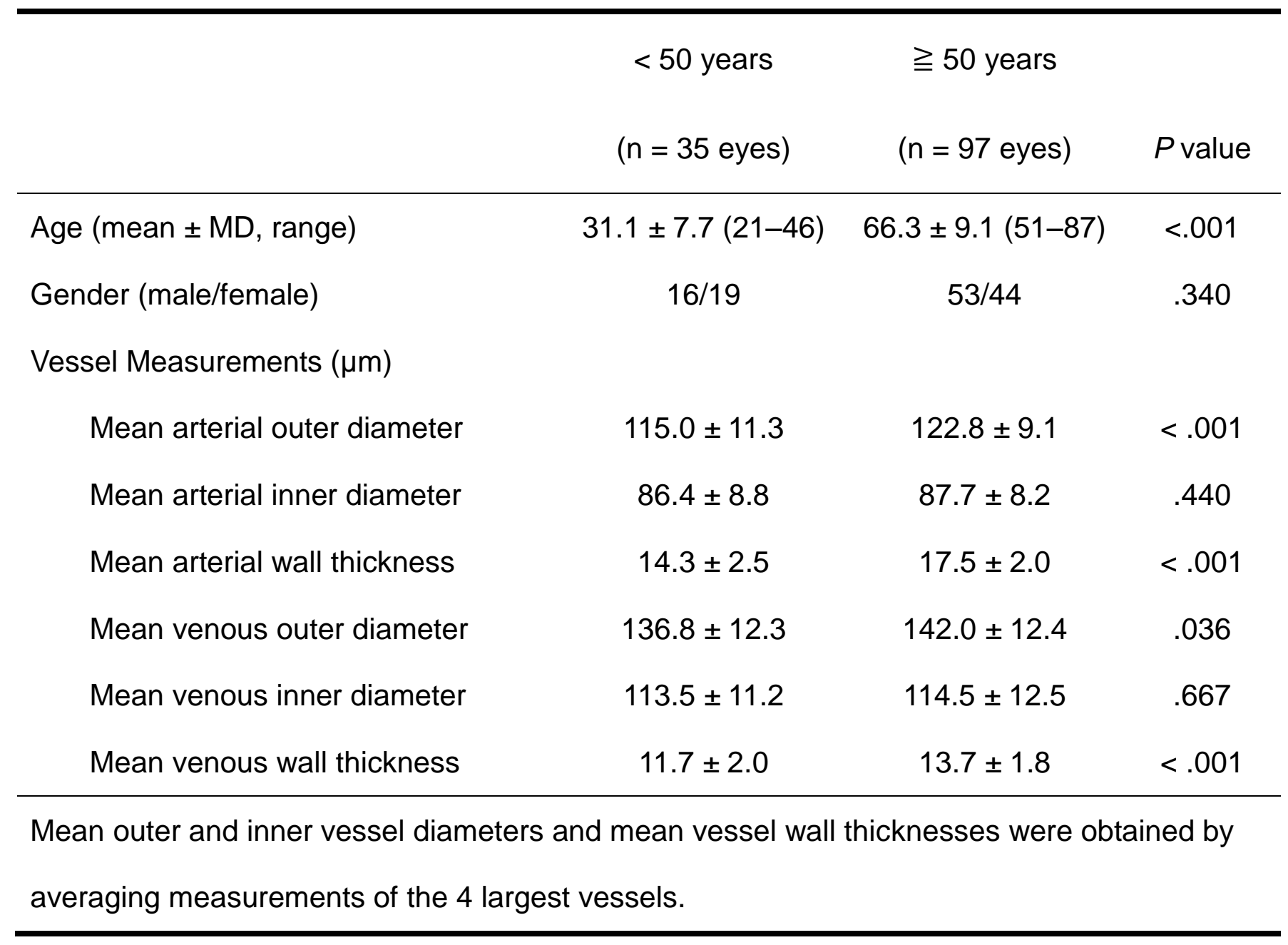


TABLE 6. Retinal Vessel Optical Coherence Tomography Measurements in Hypertension-Positive and Hypertension-Negative Groups

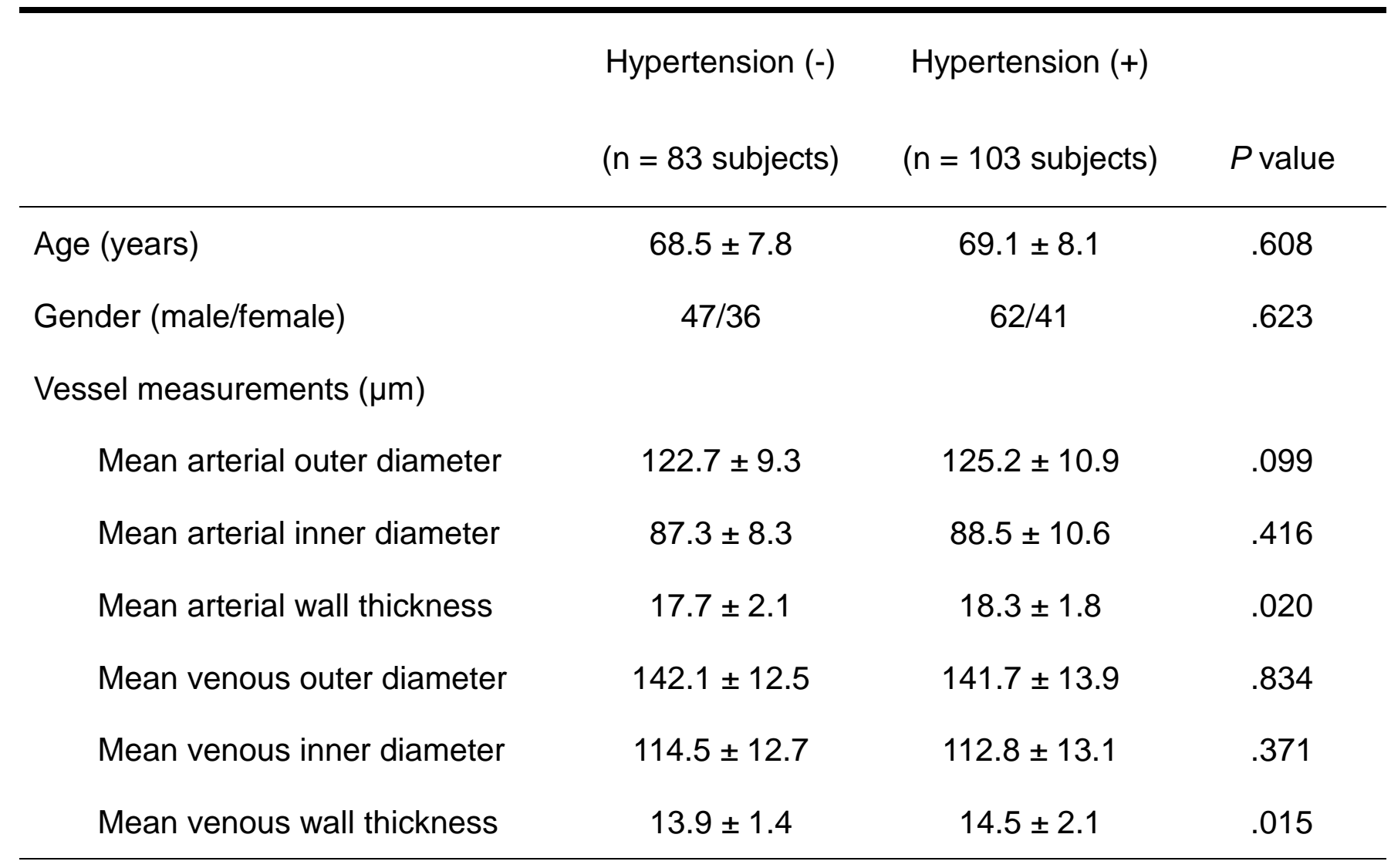

Mean outer and inner vessel diameters, and mean vessel wall thickness were obtained by averaging values of the 4 largest vessels in each subject. Subjects under 50 years of age were excluded to match ages of the 2 groups. 


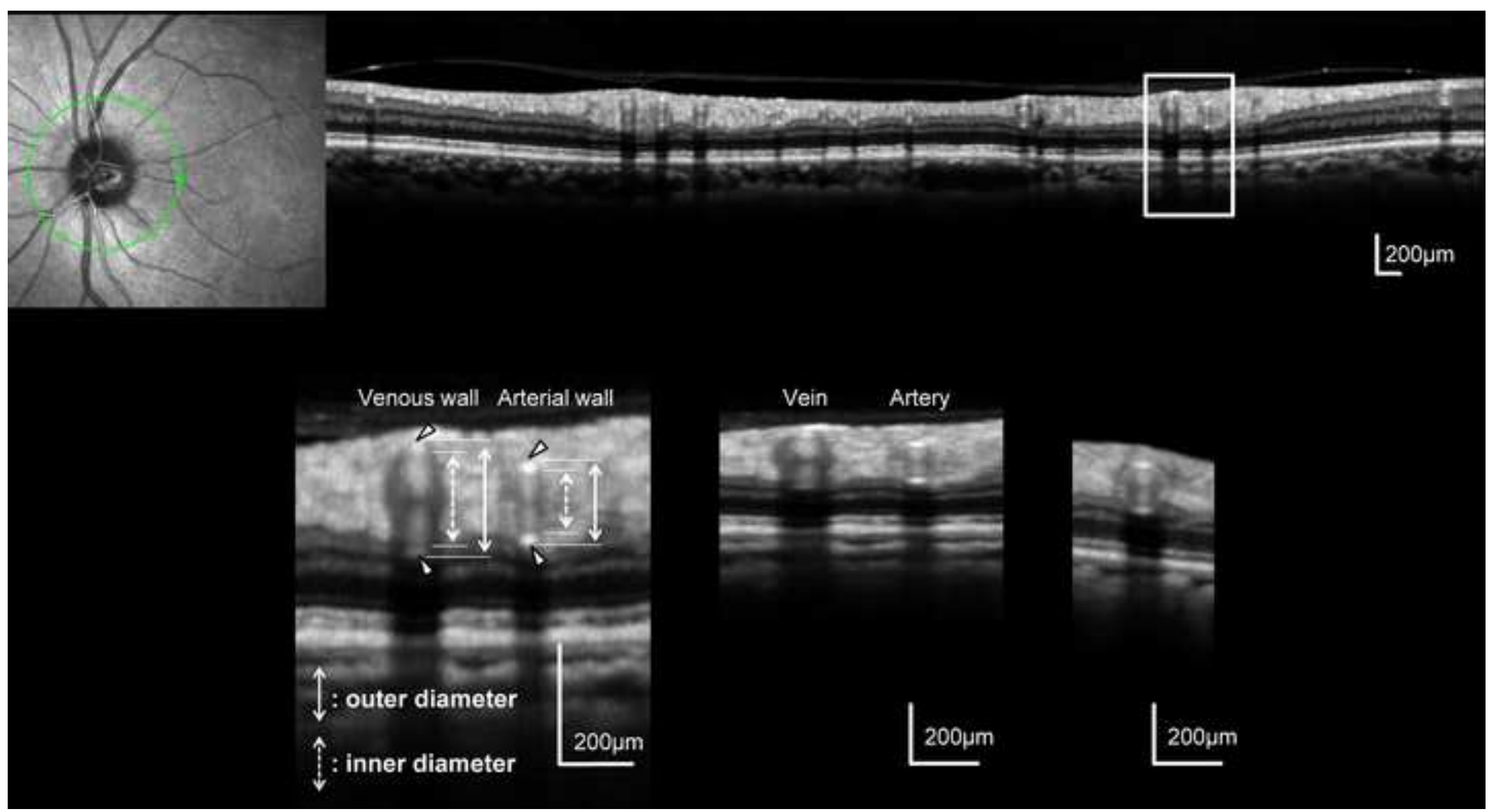

年

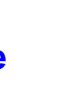



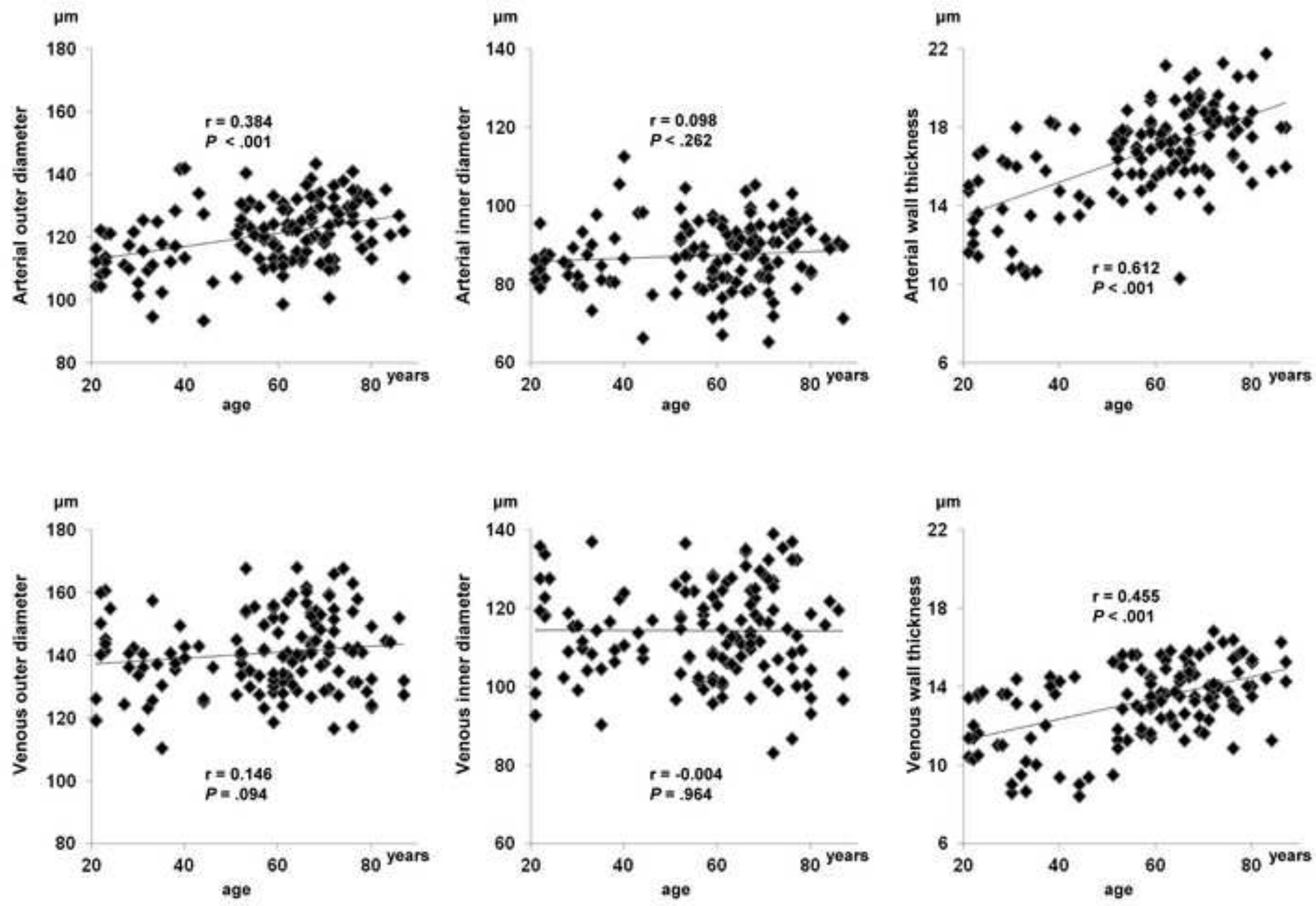

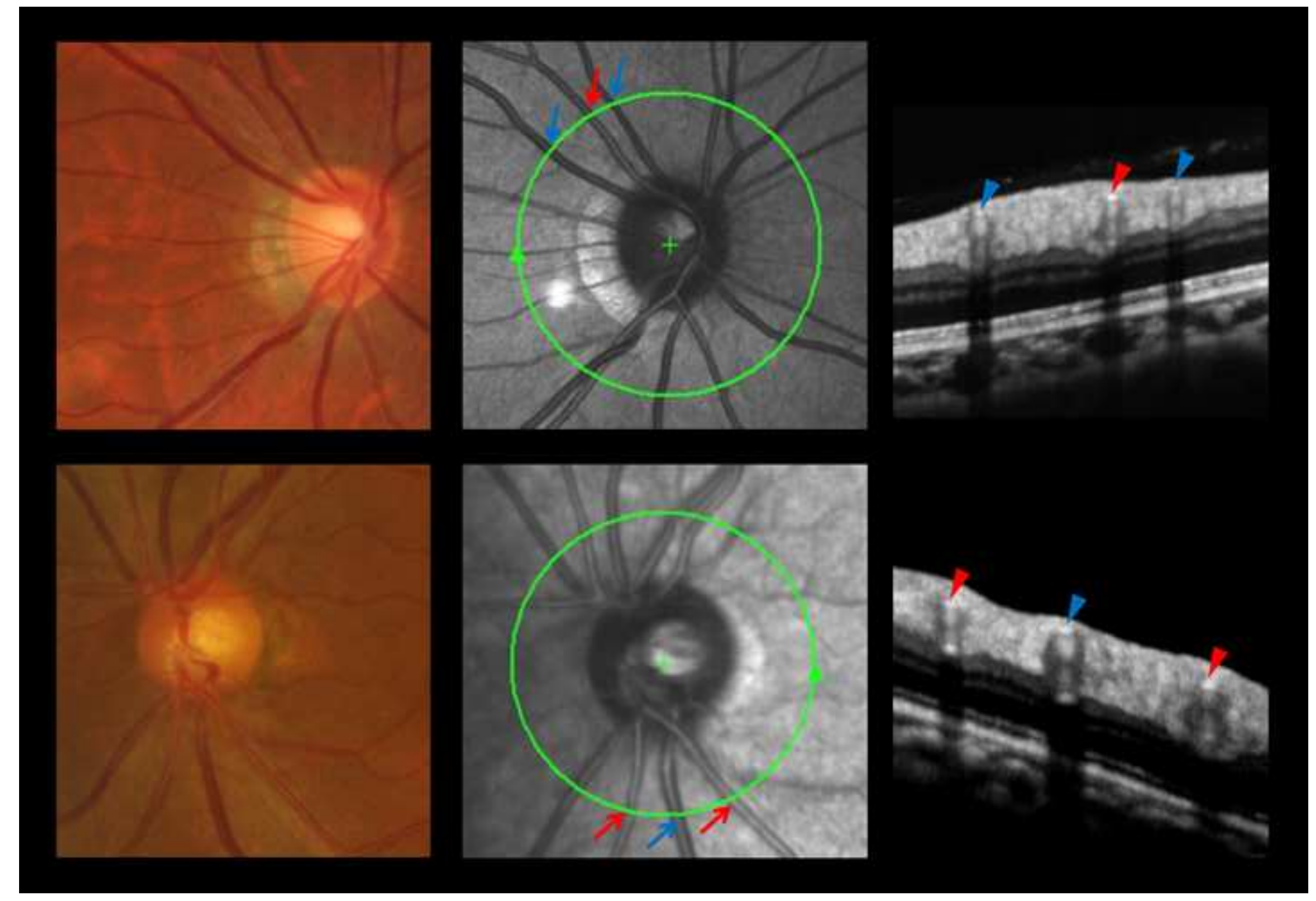

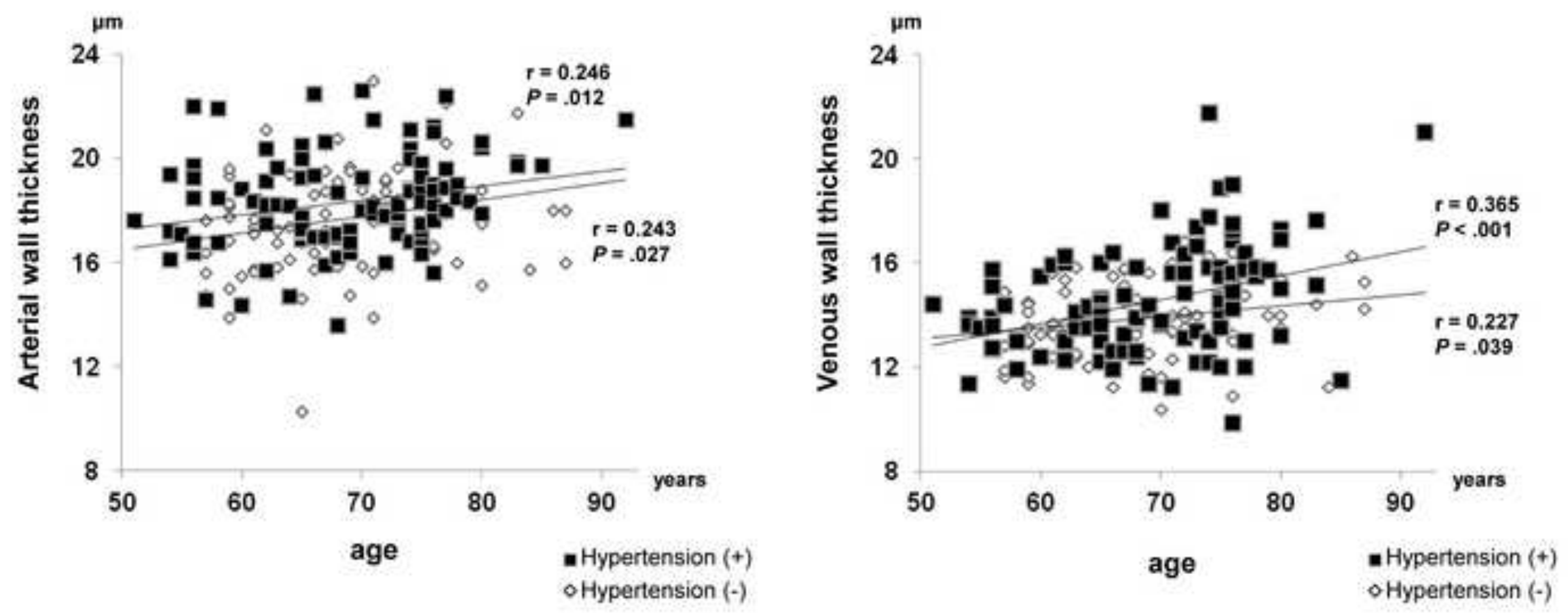
Supplementary Figure 1
Click here to download high resolution image

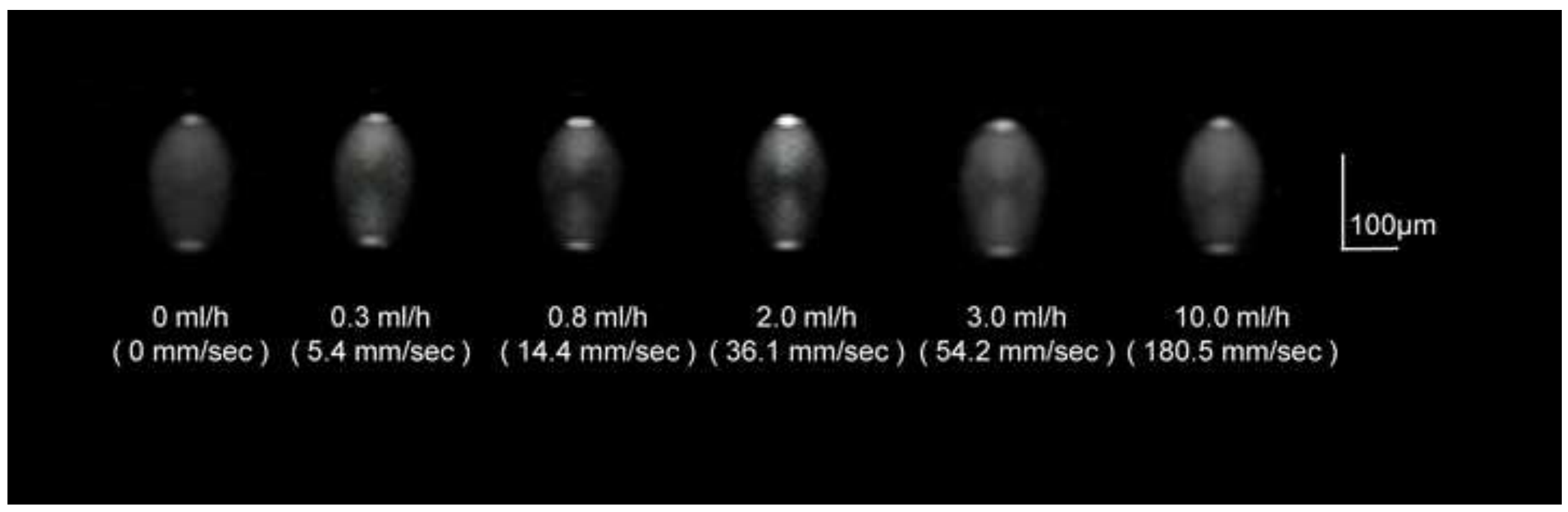

$\begin{array}{cccccc}0 \mathrm{ml} / \mathrm{h} & 0.3 \mathrm{~m} / \mathrm{h} & 0.8 \mathrm{ml} / \mathrm{h} & 2.0 \mathrm{~m} / \mathrm{h} & 3.0 \mathrm{~m} / \mathrm{h} & 10.0 \mathrm{~m} / / \mathrm{h} \\ (0 \mathrm{~mm} / \mathrm{sec}) & (5.4 \mathrm{~mm} / \mathrm{sec}) & (14.4 \mathrm{~mm} / \mathrm{sec}) & \left(\begin{array}{ll}36.1 \mathrm{~mm} / \mathrm{sec} \\ 3\end{array}\right) & (54.2 \mathrm{~mm} / \mathrm{sec}) & (180.5 \mathrm{~mm} / \mathrm{sec})\end{array}$

